\title{
Future Energy Networks and the Role of Interactive Gaming as Simulation
}

As history progresses, human beings find themselves playing non-zero-sum games with more and more other human beings. Interdependence expands, and social complexity grows in scope and depth.

- Robert Wright, Nonzero (2001)

\section{Introduction}

A lack of sustainable management of energy resources, and the linked issue of man-made climate change, continues to mount a global crisis, with most government policies and industry regulations falling short of achieving their stated goals since the 1970s (Sheppard, 2011). Increasingly organisations and governments are obliged to examine new ways of attempting to manage transitions that take into account the evolving social structures of our time: where traditional educational and political campaigns have failed, it becomes important to consider non-traditional forms of engagement. This paper discusses the application of interactive media, in particular, games and game-based methods, to support necessary transitions to more sustainable energy practices. "Energy", for the purposes of the discussion here, will be used to refer to fuel sources for domestic and commercial power, including non-renewable and renewable types such as coal, oil and solar power. We use the phrase "sustainable energy practices" to describe behaviours that seek to proactively decrease household or commercial energy use, to increase energy efficiency, and/or to adopt renewable energy products and technologies. Foregrounding the importance of systems comprehension, we argue for the strong potential of interactive games to be helpful in engaging consumers in sustainable energy practices, as they can demonstrate complex system dynamics through simulation-based experiences. ${ }^{1}$ To inform this discussion, we have consulted a range of relevant works in media studies, marketing and engagement theory and environmental communications. Our aim is to identify key ideas relevant to a discussion linking energy networks and interactive gaming in ways that can benefit ongoing efforts to mitigate climate change and interregional energy dependencies (Miller, 2010; Stackelberg \& Jones, 2014). Our approach is, in a sense, "gamer-centric"; we give considerable focus to interrogations of engagement and social change posed by gaming theorists and formative to game design itself in order to emphasise the 
usefulness of game-based principles to living and complex systems, arguing and demonstrating how the procedural nature of game space can render large-scale implications of energy decisions richly and effectively. Finally, we identify emerging potentials for sustainable energy games to link with data in the real world. Our conclusions emphasise the importance of game simulation toward the longer-term goal of cultivating more complex patterns of interaction and cultural analysis around energy use; this is based on the assertion that energy, a social resource, must be managed in ways that are equally social.

\section{Social Dimensions of Energy and Game Systems}

As a resource, energy is social in the sense that its successful delivery is now dependent upon shared infrastructures of communication and cooperation, including government policy structures and interregional and global electricity markets. Contemporarily the phrase energy network is typically used to refer to the specialised network of processes and organisations involved with electricity production and consumption, as well as information and data shared among stakeholders in this network (Tsoukalas \& Gao, 2008). Energy systems, more broadly, refers to the wider, multi-scalar interactions and interdependencies among the physical energy system and other systems such as data and information networks. As part of larger energy systems processes, communications networks are inseparable; for example, energy networks power servers which, in turn, make communications between energy grid operators possible (Gungor et al., 2011). The increased integration of energy systems, including communications and information technology elements, is a major objective of current energy grid research, aimed at more effective analysis, design and control of inter-network interactions among technical, economic, regulatory and social dimensions (Kroposki et al., 2012). As energy systems integration deepens to support the development of a cleaner and more intelligent energy infrastructure, it will be increasingly important for consumers to better understand their relationship to energy systems and to take more proactive roles in managing energy (Krätzig and Warren-Kretzschmar, 2014). This will require 
broader engagement with social resource interdependency as a matter of course, as legislation is not always an appropriate or effective driver of change (Faiers et al., 2007).

Most methods of engagement aimed at supporting energy transitions in the public and private sector, such as spanned policy changes, educational and marketing campaigns, and programmes promoting new-product uptake such as smart grid schemes, have proven to be largely ineffective (Reeves, 2015, p 110). The most often used type of educational campaign, based on presentation of fact-based, scientific evidence, does not tend to change minds or behaviours, nor do traditional marketing approaches have a predictable impact on consumer behaviour (Owen, 2004). ${ }^{2}$ There is evidence to suggest, however, that educational campaigns that are more interactive, particularly those that tap into or encourage the building of communities of practice, are able to foster more lasting change. Approaches that emphasize the role of systems - and systems thinking - can not only make energy networks more legible, it can also clarify the role of the individual as one who can produce, configure, and utilize these networks. While economic incentives, such as savings on energy bills, have been found to be helpful in promoting shifts to using more sustainable domestic and commercial energy management in the short term, they do not tend to foster long-term sustainable decision-making regarding energy use (Rowlands et al., 2003; Paladino \& Pandit, 2012). Eco-feedback devices such as smart meters, designed to increase awareness and proactivity in energy management, are shown to decline in effectiveness over time, having longer-term influence on behaviours mainly for users who were already environmentallyminded. This is perhaps partly because these devices represent only a single element of energy systems, offering users a visualization of their domestic energy consumption for example, but do not give any representation of how this affects the dynamics of the larger network (Strengers, 2011). Why energy is such a difficult arena in which to gain traction is a question with few solid answers; however, a relatively consistent suggestion among researchers has been that the invisibility and intangibility of electricity serves as a major barrier to typical marketing and intervention approaches: consumers are unlikely to strongly identify with energy brands or products due to 
their invisibility (Devine-Wright et al., 2010). At the same time, consumers are unlikely to engage with energy network organisations because the energy network itself is perceived to be highly complex (Devine-Wright et al., 2010). For both of these reasons, energy decisions and behaviours are understood to be largely dependent upon social influences and factors, such as word-of-mouth recommendations and the attitudes or purchases of friends and family (Paladino \& Pandit, 2012). Research findings across marketing, sociology and environmental planning demonstrate that similar social dynamics govern the adoption of "green" behaviours (or lack thereof), with environmentally-sensitive concepts and technologies becoming acceptable or popular according to the norms of localised groups (Clarke \& Goldsmith, 2005; Paladino \& Pandit, 2012).

In his book Smart Swarm (2010), Peter Miller uses the phenomenon of a standing ovation to illustrate how cascades of conscious and unconscious social signals instigate waves of collective response-a phenomenon that affects countless actions, ranging from whether people send their children to public schools or private schools to whether they put on weight (p. 262). While complexity is a term with several definitions based upon a number of related applications in different fields, here we borrow from Parrish and Edelstein-Keshet (1999) who define complexity as a system in which "large populations of units can self-organize into aggregations that generate pattern, store information, and engage in collective decision-making" (p. 99). Online, opportunities for aggregation of social units are ubiquitous and amplified. "Local” groups once limited to geographic locality are extended to potentially much larger connected communities. In complex systems, waves of connected behaviours (from the coordinated movement of a flock of birds to the coordinated movement of a standing ovation or traffic jam) reflect rules that do not operate upon isolated individuals operating at mass scales, often with surprising results (Parrish and EdelsteinKeshet, 1999). Similar dynamics occur in social gaming environments, where groups of individuals may act collectively in response to (virtual) environmental challenges to develop adaptive coping strategies (Gee, 2013). As in ecosystems, social game systems are more resilient to change thanks to coordinated processes of self-organisation and adaptation (Gyrd-Jones \& Kornum, 2013; Foth et al., 
2011). ${ }^{3}$ While the cultural, biological and socioeconomic systems governing energy behaviour change are extremely complex in their own right, the possibilities for social games to influence their dynamics has not yet received a large amount of serious enquiry, despite much of the foundational research demonstrating that collective play, and online socializing, both contribute to enhanced problem-solving capacity through what can broadly be described as systems thinking (Churchman 1967, Rittel \& Webber 1973 et al).

\section{Games as Legible Simulations of (Energy) Systems}

Bogost's concept of procedural rhetoric focuses upon the power of games to persuade; essentially, according to Bogost, games can deliver meaningful experiences of concepts and perspectives via step-by-step processes of interaction or procedure, which can be used to enact arguments (Bogost, 2010). Though based on classical rhetorical theory, procedural rhetoric includes integrations of contemporary, digital design elements that are able to represent dynamic models effectively in the form of interactive experiences (p. 28). A number of theorists have argues that these interactive models can represent actuality more effectively than other forms of media; Gonzalo Frasca has argued, for example, that simulations in game worlds are not abstract because they are based on real relationships, with actions motivated in ways that link to realistic values (2003, p. 223; Squire, 2003). This view of game as system chimes with the arguments of Hayles, who writes that contemporary narrative is, and should be, "a kind of textual android created through patterns of assembly and disassembly," whereby there is no natural story beyond the story of relationshipbuilding, or network-building, within the universe of the text; the "argument" does not put forward an objective or subjective point of view, but rather demonstrates systemic and inter-systemic dynamics as a truth in itself. 4

In this sense, games may express our networked contemporary reality in very useful way. Vervoort et al. note, in their 2010 study on interactive media applications in environmental stakeholder networks, human and natural systems, what they term social-ecological systems, are 
non-linear, existing at vast and multiple scales whose complexity is not reflected by many current communications practices. "Digital games," according to this study, are "communication arenas with internal rules and temporal dynamics that can lead to complexity both as emergence and as conscious design," including adaptations to and production of transformations in the environment. As such, the authors argue, games "are particularly suited to be linked to dynamic scientific models in order to give participants understanding of spatial-temporal dynamics," but note that, so far, games that reach this level of complexity are big-budget commercial games rather than educational or socially motivated games, "therefore much of this broad potential for complex system dynamics still remains untapped" (p. 610). ${ }^{5}$ The focal idea of this study is that game environments can function effectively as microcosms of larger complex systems, in which personal and collective action incite chains of temporal and systematic reaction (like the proverbial butterfly flapping its wings in Central Park, and causing a hurricane in Guatemala). Games simulate the consequences of interconnectedness on large scales, demonstrating the complicated patterns of proliferation of cause and effect as these could or do play out in reality; they are eco-simulations of action and reaction (see also Crawford, 1982). A number of theorists have suggested that game players seem particularly well-equipped to comprehend system dynamics in broader scenarios (Murray, 1998; McGonigal, 2011; Whitton, 2012). Although game systems are simulations structured by computational algorithms rather than environmental conditions, this fact seems to matter approximately as much as it matters in ecological modelling situations: done well, games can model actual scenarios relatively effectively.

Fate of the World: Tipping Point (2011) is a game that uses simulation to challenge players to think through energy issues realistically and pragmatically. The game depicts a near-future scenario in which players must navigate a number of natural and man-made disasters caused by climate change, where game play focuses player efforts upon planning appropriate responses and managing resources in sustainable ways. This includes managing various crises related to, for instance, fuel scarcity and rising sea levels. Through narrative and interactivity, Tipping Point 
illustrates connections between the environmental and social problematics of each disaster, as well as between localised and global effects of player decisions. Beyond simply managing local issues like resource shortages, players must also address broader, more abstract concerns such as global Human Development Indexes, and to do so must understand the relationships between these. ${ }^{6}$ To succeed in this game, players must understand the complex interconnectedness of inputs and outputs of the dynamic system; through trial, error and feedback, they configure and reconfigure the system to produce desired consequences. Though the game world is complex, it is simultaneously designed to be legible, allowing multiple play-throughs in order to intelligibly demonstrate outcomes of interactions and interventions. A variety of outcomes are possible relative to any given task; in other words, players can reconfigure sequences of interactive events to simulate different outcomes. Tipping Point's interface also provides broad-scale feedback via a globe view, a dynamic visualisation of how game-play is affecting the health of the (virtual) planet and a simulation of real world system dynamics.

Frasca argues that simulation and the outcomes of simulation are the core issues of most games, where the experimental structure of the dynamic game system allows user-friendly data modelling - a dynamic experience of realistic change over time (2004, p. 86). ${ }^{7}$ Bogost's procedural rhetoric was developed to investigate this very issue, its basis is the way in which computers "run processes that invoke interpretations of processes in the material world," largely by drawing users through the system of algorithmic experience and response, in which the algorithms shape the simulations and allow the player to continuously reconfigure in-game reality (2007, p. 5).. Or, as Mackenzie Wark has it, the "artful surfaces of the game are just a way for the gamer to intuit their way through the steps of the algorithm" (1994, p. 120). For the intuition process to function as it should, however, a particular kind of interactivity is necessary, wherein a user's actions have actual significant impact on virtual outcomes and environments are "meaningfully responsive" to user input, meaning the players has agency and effect in the simulation (Bogost, p. 42; Salen \& Zimmerman 2004, p 34). In this sense, games offer a way of interacting and also specific contexts to 
act within, including social and environmental contexts for energy resource consumption that make the modelling of scenarios more realistic. In "Gaming the Future of an Urban Network", the authors find that combinations of game dynamics and modelling scenarios allow users to better comprehend the complexity of city planning and development, partly because both methods "root in a 'what if...' type of thinking" while encouraging complementary processes of conceptual and experiential analysis (Mayer et al., 2004, p. 314). Will McDowall suggests something similar in his article investigating transitions to hydrogen energy, finding that there can be extremely productive "dialogue" between data-driven modelling and narrative-driven scenario building (2014). Oscillations between hypothetical and practical problem-solving, open and constrained ways of thinking about energy issues, can engage players in critical processes that allow them to not only better understand how real-world systems operate, but to cognitively deconstruct systems operation, inciting interrogations of problematic elements and proposing solutions.

\section{Narrativising Data: Games and Emotion}

Broadly speaking, narrative is the engine of the analytical process: in daily life narrative motivates continuous analysis of relationships. Janet Murray has rightly pointed out that stories are a way to make the abstract not only legible but interesting: very few of us would "curl up at night with ... Propp's abstract morphemes" (p. 203). As flexible simulations of reality, game structures support critical and analytical processes by providing narrativisation of algorithm; game simulations, procedurally written and systemically manifest, are effectively abstract equations materialising under virtual but realistic conditions. ${ }^{8}$ In this sense, games are far more compelling for the average consumer than raw data or even pre-interpreted data, both of which have been found to be unlikely to influence energy behaviours on their own (Haggett, 2014; Stephenson et al., 2010). By contrast, providing actual or hypothetical data formatted as stories or challenges, and allowing users to experience, interpret and have conversations around data as a dynamic system, is shown to have some effect (Deighton, Romer, \& McQueen 1989; Escalas 2004; Stackeberg \& Jones, 2014). 
The capacity for games to work across textual registers allows a special kind of narrative that is flexible in terms of scale (as with the multi-scalar views of a game like Tipping Point) as well as perspectival position in space, for example street view versus aerial view, or even positions in the virtual body-space of various characters. Collapsus (2011) an interactive fiction, illustrates the point; marketed as "a new experience in transmedia storytelling," this complex work combines traditional documentary techniques with new forms of interactivity to create a combination of narrative and game. In Collapsus, climate change is framed through multiple interlinked perspectives: interchangeable panels fit within a single screen, one panel which comprises the interactive timeline, one showing an interactive globe that expresses interdependencies among conditions in the physical environment, energy systems and political systems, and another panel that delivers documentary-style clips and character commentary providing the players with narrative context and feedback (see Figure 1). While players consider the potential social and political issues that arise from the energy management decisions they make in the game, the effects of these decisions play out in parallel, demonstrating local, personal and global impact across these multiple views. At the same time, the viewer can easily switch between the panel perspectives, and can pause the action at any time to investigate information and points of narrative more deeply. The evocation of simultaneous perspectives of reality demonstrates the complexity of these processes more effectively than many other media could do, employing the decentralisation of modern communication technologies - where multiplicity is native - to suggest fluid boundaries between causal sequences and perspectival views. In games like Collapsus, players are encouraged to consider links between energy systems, social connections, management decisions and local outcomes, having influence or direct decision-making power regarding, for example, national policies regarding energy production and consumption. This network of conditions then plays out in the lives of characters; it could be argued that this increases the effect of the procedural argument by asking viewers to identify with these characters. 
Data is also shown to become compelling when combined with motivating tasks, stories or instructions. Games achieve this by integrating narrative with puzzles, social challenges, and structured systems of feedback that provide emotional rewards (McGonigal 2011). The effectiveness of "gamifying" data in this way has been demonstrated by the success of crowdsourcing games like Folding@Home, which has gathered protein folding simulations from over 327,000 users since 1999, and Investigate Your MP's Expenses (2009), an app that has, as of January 2015, crowdsourced analysis of over 160,000 pages of UK government personal expense documents. ${ }^{9}$ Eskom Energy Planner (2013) is another to add to the list of gamified simulations of energy systems, but conceived differently from those discussed so far: resembling games such as SimCity (1989) and The Sims (2000) in its design. Energy Planner's narrative unfolds as a result of resource management decisions, in which players effectively design energy infrastructure, policy and operations on government and utility levels, viewing the city aerially to plan and achieve, for instance, installations of power stations and energy grid components. Energy consumption is then rendered realistically on domestic and local levels. Even more explicitly than Collapsus, Energy Planner asks players to balance data sets, visualised in the game as levels corresponding to financial, ecological, and economic states, as well as taking responsibility for the more general well-being, of the community. The aim is to create a sustainable local energy management system.

In contrast to fact-based campaigns, the effectiveness of energy games relies in part on processes of shifting between macro and micro energy management scenarios, in effect personalising relationships between the network of domestic energy transactions and the network of larger-scale factors and agents of energy production, supply and delivery. In order to be engaging, simulations require a degree of enthusiasm on the part of participants (or game players), which translates to emotional investment in virtual outcomes (Sherry et al., 2006). Highly emotional stimuli, perhaps not surprisingly, are processed more quickly and hold our attention longer than less emotional stimuli (Eastwood, Smilek, \& Merikle, 2001), with positive emotion having a greater effect than negative in terms of emotional arousal and social sharing, all factors that are likely to 
have an impact on the media and arguments with which consumers will engage (Berger \& Milkman, 2012).

\section{Mixing Simulations and Reality}

The emerging field of "serious games" builds on the potential of game simulations to incite emotional investment, with games designed to harness desire among gamers to be of service to realworld causes as the goal, rather than the side effect, of gaming (McGonigal, 2011). While typical interactive games may comprise design processes aimed at influencing players by stimulating introspection and self-reflection, serious games are designed to educate and influence player attitudes and actions in the real world, and are likewise often discussed in terms of their effects on the ecological, cultural and financial systems that they simulate or critique (Boyle et al., 2011; Vasconcelos et al., 2009). Many serious games are aimed at increasing social awareness of realworld issues through simulation, like Darfur is Dying, a video game that interactively portrays the experiences of refugees living in the Darfur region of Sudan (interFuel, 2006). ${ }^{10}$ Another example is Spent (2011), in which players negotiate a complex, lifelike system comprising domestic, professional and financial responsibilities and variables - think The Game of Life on a digital platform - but designed to reflect the actual current employment realities of blue collar America. A major aim of this game is to explore the systemic nature of unemployment and homelessness.

The direction of recent technological history is toward increasingly frictionless interfaces. The game controllers and computer screens that separate users from networked system interactions are becoming thinner, more transparent, even invisible (Gabrys, 2014). Simultaneously, the automation of data events - for example, the automatic, invisible changes to time zones on mobile phone or laptop interfaces when we travel, or the real-time reporting of household energy use to servers for analysis - is moving us closer to a point of critical mass at which the invisibility of data flows and human-system interaction will be normalised, a sort of frictionless data ecosystem. This is the proposed outcome of the Internet of Things (IoT), the embedding of network technologies 
integrally into lived environments that allows everyday objects to become augmented with communications capacities (Gubbi et al., 2013). The IoT represents an interconnected, intelligent, real environment in which the feedback we typically associate with screen devices increasingly arrives via many other avenues, including resource-management objects like cars, electricity meters, lawn mowers, water supply meters, and refrigerators (Srivastava \& Vakali, 2012). The concept and the practical implications of the IoT are still developing, and it is only in the past several years that the data resulting from the network interconnections of objects and machines have been put to use in any meaningful way; however, for game designers, and particularly game designers interested in promoting sustainable resource management, the IoT opens up a host of possibilities for meaningful system interaction (Foster \& Linehan, 2013; Gabrys, 2014).

It is reasonable to surmise that we will begin to see an enrichment of the informational environment surrounding energy use, in which consumers receive a plethora of feedback on energy habits from things and from each other through things. Indeed that has already begun, with the popularisation of smart meters and other personal energy monitoring devices (Pierce \& Paulos, 2012). Google's Project Nest is a recent innovation of this type, comprising a "learning thermostat" that adapts to domestic patterns with networked carbon monoxide and smoke detectors, and a thermostat that "learns" a user's movements to heat the house in anticipation of the user returning home from work in the evening. ${ }^{11}$ Similar things can be achieved with less sophisticated systems using live data, however, and the implications for gaming with real-world impact are promising. The game Run This Town (2013), for example, as piloted by the Australian Bureau of Statistics (ABS), used census data to create a dynamic, playful experience of resource management on a townplanning level with a good deal of relevance to the typical Australian town (ABS 2013). This game allows players to play in a world governed by interaction with live data, blurring the lines between the play space and the urban space. Opower, who partnered with Facebook in 2012 to launch a "social energy app" aimed at increasing household energy efficiency, has reportedly saved consumers more than 400 million US dollars in energy bills by gamifying the domestic energy 
management process (Grant, 2014). It should be noted that the games discussed here represent only a small fraction of those which have been, and are being, developed, demonstrating that gamers can (and do) provide productive insight into the real problems that games simulate. The IoT in particular offers numerous potential avenues for connecting consumers to other agents within the energy network, such as government bodies and grid operators, as well as feeding into live data sets that may inform decision-making around planning or energy grid upgrades. Games like Energy Planner can be taken further to become more than simulation; at the moment, outcomes in games like this are typically governed algorithms based on realistic data; as organizations become more adept at harnessing actual live data from the IoT into living, dynamic feedback loops, games can be increasingly governed by real data.

Broadly speaking, live energy grid, economic, census, and financial data could be harnessed to create increasingly practically relevant game design approaches, to pose realistic or actual problems to which players can ostensibly offer insightful solutions. While productive contributor status is likely to have personal value for game-players, especially if social gaming continues its trend of rising popularity, there is a broader value contained in the habituation of productive contribution as a normal part of game-play and resource management. Furthermore, games can be used strategically to address issues that invite collective problem-solving and community energy interest, for example community-owned and operated energy production networks and microgeneration schemes. Indeed, the integration of game simulations and real data and scenarios has exciting potentials, indicating a serious resource for generating energy solutions and changing energy behaviours.

\section{Concluding Remarks}

It seems likely that proactive engagement economies for energy use will become more typical as home and business owners are forced to recognise the rising costs of energy inefficiency and using unsustainable energy sources, and as alternatives such as micro-production and self-management 
devices become more available. A number of interactive media practitioners and smart grid developers have already begun the task of making more dynamic relationships a reality, where a common theme of many approaches to grid enhancement thus far has been to increase integrated informatics and two-way communications within energy systems. Digital social networks are now being applied in specialised ways to energy network problems related to pricing, load and curtailment, blackout, improvement of system reliability, robustness, availability, and scalability (Gungor et al., 2011; Simmhan et al., 2011). This is being achieved through tools like real-time social media data analysis to monitor and predict energy usage, social media supported shift-and-save models, and energy-use mobile apps (see for example Sheppard, 2011). At the same time, over the last forty years consumers have demonstrated a growing desire to engage in dynamic informational environments that require active, playful contribution. Energy organisations are likely to benefit from the creation of intelligent systems in which consumers can simultaneously think about and play with aspects of energy consumption, using and building on existing skill sets and social networks to become more effective energy managers (Boyle et al., 2010; Kratzig \& WarrenKretschmar, 2014).

To stimulate future growth in this area, it will become increasingly important for those shaping policy and energy engagement campaigns to consider energy and communications networks as linked and dialogic systems, with linked and dialogic ends. Deep systems integration will require, to varying and increasing degrees, systems comprehension on the part of consumers as well as network operators (Vervoort et al., 2010). Likewise, facilitating productive dialogue among stakeholders is a key component of achieving larger sustainable energy goals, a point which has become more actively reflected in critiques of planning and environmental policy in recent years (Evans-Cowley \& Hollander, 2010; Bickerstaffe, 2013). It will be increasingly important that organisations relate to individual consumers as mutually productive contributors in solving broad energy problems. ${ }^{12}$ This must go beyond, as well, the segments of the population who are already interested in environmental responsibility and/or adopting new technologies; reaching those who 
are not environmentally inclined will as always represent the greatest challenge in developing tools that are effective in influencing energy use. As a genre of entertainment media, digital games have a unique advantage in that they are often social as a rule, and spread socially: if you can achieve a game with simplicity, some addictive qualities, and engage a critical mass of players, it will spread on its own - and with it, perhaps, embedded changes in thinking about the situations it represents in the real world. There are a number of hugely popular resource management games, like Farmville (2009), Clash of Clans (2012) or Mafia Wars (2009), that could serve as models of social gaming that work; these are games proven to have a wide demographic appeal (plus a larger than average player base of females, over-40s, and teens - all outside the typical "gamer" demographic categories) (Santovec, 2011).

The relevance of games in helping to change how we relate to our resources, environments and social structures is likely to go well beyond the single intervention or campaign, and even beyond larger goals such as meeting regional sustainable energy targets. As simulation, games are less ephemeral than digital media, and have been around seemingly since our human beginnings, as simulations of real conflicts and challenges (Lancy, 2015). Our modern, highly visual digitised networks simply expanded the scale of connectivity in games and thus the range of networks across which playful cooperation can occur. At the same time, the physical networks that transmit information as well as the structure of information itself is evolving to be increasingly decentralised, mobile, and adaptable. ${ }^{13}$ Games are extremely well suited to this paradigm, able to mount arguments and enact realities in ways that emphasise our participatory roles in complex systems, while simultaneously interrogating the nature and effectiveness of those systems. Regarding our management of energy resources and social responsibility more broadly, the multiple, multi-scalar perspectives that interactive games encourage may, by supporting us in understanding our systemic positions more clearly, help us make more conscious and humane choices in the future.

\section{Acknowledgements}

Many thanks to the University of Ulster and B9 Energy for supporting this research. 


\section{References}

1. Atkinson, S., (2014). Beyond the Screen: Emerging Cinema and Engaging Audiences. New York: Bloomsbury.

2. Berger, J. \& Milkman, K.L. (2012), “What Makes Online Content Viral?” Journal of Marketing Research, 49(2), p. 192-205.

3. Bickerstaffe, S. (2013). Building Tech-powered Public Services. UK Institute for Public Policy Research.

4. Bogost, I. (2009). "Persuasive Games: The Proceduralist Style," Gamasutra [Accessed 20th Jan 2015] [Online] Available from: http://www.gamasutra.com/view/feature/132302/persuasive_games_the_.php

5. Bogost, I., (2010). Persuasive Games: The Expressive Power of Videogames. Cambridge, Massachusetts: MIT Press.

6. Boyle, E., Connolly, T. M., \& Hainey, T. (2011). “The Role of Psychology in Understanding the Impact of Computer Games. Entertainment Computing, 2(2), p. 69-74.

7. Cass, N., \& Walker, G. (2009). “Emotion and Rationality: The Characterisation and Evaluation of Opposition to Renewable Energy Projects." Emotion, Space and Society, 2(1), 62-69.

8. Churchman, C.W.(1967).Wicked problems. Management Science, 14(4), B141-B142.

9. Clark, R. \& Goldsmith, R. (2005). “Market Mavens: Psychological Influences.” Psychology and Marketing 22, p. 289-312.

10. Crawford, C., (1984). The Art of Computer Game Design. New York: McGraw-Hill Osborne Media.

11. De Freitas, S. (2011). “Games for change." Nature, p. 3-4.

12. Deighton, J., Romer, D. \& McQueen, J. (1989). “Using Drama to Persuade.” Journal of Consumer Research, 16(3), p. 335-43.

13. Devine-Wright, P., Devine-Wright, H., \& Sherry-Brennan, F. (2010). “Visible Technologies, Invisible Organisations: An Empirical Study of Public Beliefs about Electricity Supply Networks. Energy Policy 38(8), p. 4127-4134.

14. Eastwood, J. D., Smilek, D., \& Merikle, P. (2001). “Differential Attentional Guidance by Unattended Faces Expressing Positive and Negative Emotion." Perception \& Psychophysics, 63(6), p. 1004-1013.

15. Entertainment Software Association (2014) Essential Facts About the Computer and Video Game Industry 2014 Sales, Demographic and Usage Data [accessed 13 th January 2015] Available from: http://www.theesa.com/wp-content/uploads/2014/10/ESA_EF_2014.pdf 
16. Escalas, J. E. (2004). “Narrative Processing: Building Consumer Connections to Brands.” Journal of Consumer Psychology, 14(1), p. 168-80.

17. - - - (2007), "Narrative Versus Analytical Self-Referencing and Persuasion," Journal of Consumer Research, 34(4), p. 421-9.

18. Evans-Cowley, J., \& Hollander, J. (2010). “The New Generation of Public Participation: Internet-based Participation Tools." Planning Practice and Research, 25(3), p. 397-408.

19. Faiers, A., \& Neame, C. (2006). "Consumer Attitudes towards Domestic Solar Power Systems." Energy Policy, 34(14), p. 1797-1806.

20. Flanagan, M., (2013). Critical Play: Radical Game Design. Cambridge, Massachusetts: MIT Press.

21. Foster, D. \& Linehan, C. (2013). “Liking” Carbon: Can Social Media Play a Role in Carbon Management? Carbon Management 4(1), p. 1-4.

22. Fredericks, J., \& Foth, M. (2013). “Augmenting Public Participation: Enhancing Planning Outcomes through the Use of Social Media and Web." Australian Planner, 50(3), p. 244-256.

23. Frasca, G., (2004). “Videogames of the Oppressed: Critical Thinking, Education, Tolerance and Other Trivial Issues" in Wardrip-fruin, N. \& Harrigan, P. (Eds.), First Person: New Media as Story, Performance and Game. Cambridge, Massachusetts: MIT Press, p. 85-94.

24. Friedman, T. (2006). “Civilisation and Its Discontents: Simulation, Subjectivity, and Space." Games Research [Online] [Accessed 23 Feb 2015] Available from: http://gameresearch.com/index.php/articles/civilization-and-its-discontents-simulation-subjectivity-andspace/

25. Gabrys, J. (2014). “Programming Environments: Environmentality and Citizen Sensing in the Smart City." Environment and Planning D: Society and Space, 32(1), p. 30-48.

26. Gee, J.P. "Learning Systems, Not Games." Texas Education Review 1 (2013).

27. Grant, R. (2012). “After saving people $\$ 416.5 \mathrm{M}$ in energy bills and 3.7B kilowatts, Opower files to go public." Venturebeat. [Accessed 26 Jan 2015] Avaiable at http://venturebeat.com/2014 /02/12/ after-saving-people-416-5m-in-energy-bills-and-3-7b-kilowatts-opower-secretly-filesto-go-public/ ]

28. Gubbi, J., Buyya, R., Marusic, S., \& Palaniswami, M. (2013). “Internet of Things (IoT): A Vision, Architectural Elements, and Future Directions." Future Generation Computer Systems, 29(7), p. $1645-1660$.

29. Gungor, V. C., Sahin, D., Kocak, T., Ergut, S., Buccella, C., Cecati, C., \& Hancke, G. P. (2011). "Smart Grid Technologies: Communication Technologies and Standards." IEEE Transactions on Industrial Informatics 7(4), p. 529-539. 
30. Gyrd-Jones, R. I., \& Kornum, N. (2013). "Managing the Co-created Brand: Value and Cultural Complementarity in Online and Offline Multi-stakeholder Ecosystems." Journal of Business Research, 66(9), p. 1484-1493.

31. Haggett, C. (2009). "Implications of alternative mitigation responses: Renewable energy" in Lever-Tracy, C. (Ed.) Handbook of Climate Change and Society, London: Routledge.

32. Haggett, C. (2014). "Planning and Persuasion: Public Engagement in Renewable Energy Decision-Making" in Patrick Devine-Wright (Ed.), Renewable Energy and the Public: From NIMBY to Participation. Lond: Routledge.

33. Hayles. N. K. (1999). How We Became Posthuman: Virtual Bodies in Cybernetics, Literature, and Informatics. Chicago: University of Chicago Press.

34. Hayles, N. K. (2007). “Intermediation: The Pursuit of a Vision.” New Literary History, 38(1), p. 99-125.

35. Henderson, B. (2013). Rethinking the Internet of Things: A Scalable Approach to Connecting Everything. New York: APress Publishing.

36. Klabbers, J. (2011). “Tensions Between Meaning Construction and Persuasion in Games." Game Studies 11(2) [accessed 10th January 2015] Available from: http://gamestudies.org/1102/articles/klabbers_book_review

37. Krätzig, S., \& Warren-Kretzschmar, B. (2014). “Using Interactive Web Tools in Environmental Planning to Improve Communication about Sustainable Development." Sustainability, 6(1), p. 236-250.

38. Kroposki, B., Garrett, B., Macmillan, S., Rice, B., Komomua, C., Malley, M. O., Kroposki, B. (2012). “Energy Systems Integration A Convergence of Ideas.” Springfield, VA: National Renewable Energy Laboratory \& U.S. Department of Commerce.

39. Lancy, D. F. (2015). “Mapping the Landscape of Children's Play." Utah State University Digital Commons: Sociology, Social Work \& Anthropology.

40. Sherry, J., Lucas, K., Greenberg, B., \& Lachlan, K. (2006). "Video Game Uses and Gratifications as Predictors of Use and Game Preference." Playing Video Games: Motives, Responses, and Consequences (2006): p. 213-224.

41. Mayer, I., Carton, L., de Jong, M., Leijten, M., \& Dammers, E. (2004): "Gaming the Future of an Urban Network." Futures 36.3 (2004): 311-333.

42. McDowall, W. (2014). "Exploring Possible Transition Pathways for Hydrogen Energy: A Hybrid Approach Using Socio-technical Scenarios and Energy System Modelling. Futures, 63, p. 1-14.

43. Miller, P., (2010). The Smart Swarm: How to Work Efficiently, Communicate Effectively, and Make Better Decisions Using the Secrets of Flocks, Schools, and Colonies. (2ND ed.) New York: Avery. 
44. Murray, J., (1998). Hamlet on the Holodeck: The Future of Narrative in Cyberspace. Cambridge, Massachusetts: MIT Press.

45. Nakarado, G. L. (1996). "A Marketing Orientation is the Key to a Sustainable Energy Future." Energy Policy, 24(2), p. 187-193.

46. Nest (2015). Works with Nest. Available at: https://www.youtube.com/watch?v=bPdltu93pM. [accessed 25th February 2015].

47. Owen, A. D. (2004). "Environmental Externalities, Market Distortions and the Economics of Renewable Energy Technologies." The Energy Journal, p. 127-156.

48. Paladino, A., \& Pandit, A. P. (2012). “Competing on Service and Branding in the Renewable Electricity Sector." Energy Policy, 45(2), p. 378-388.

49. Parrish, J. K., \& Edelstein-Keshet, L. (1999). “Complexity, Pattern, and Evolutionary Trade-offs in Animal Aggregation." Science 284, p. 99-101.

50. Pierce, J., \& Paulos, E. (2012). “Beyond Energy Monitors: Interaction, Energy, and Emerging Energy Systems" in Proceedings of the SIGCHI Conference on Human Factors in Computing Systems, p. 665-674. Raleigh, NC: Association for Computing Machinery.

51. Prothero, a., McDonagh, P., \& Dobscha, S. (2010). “Is Green the New Black? Reflections on a Green Commodity Discourse." Journal of Macromarketing, 30(2), p. 147-159.

52. Reeves, B., Cummings, J., Scarborough, J., \& Yeykelis L. (2015) “Increasing Energy Efficiency With Entertainment Media: An Experimental and Field Test of the Influence of a Social Game on Performance of Energy Behaviours." Environment and Behaviour 47(1), p. 102-115. New York: Sage.

53. Rittel, Horst W. J.; Melvin M. Webber (1973). "Dilemmas in a General Theory of Planning" Policy Sciences 4: 155-169

54. Rowlands, I.H., Parker, P., Scott, D. (2003). “Consumers and Green Electricity: Profiling Potential Purchasers." Business Strategy and the Environment 12

55. Rogers, E. M. (2010). Diffusion of Innovations (4th ed.). New York: Simon and Schuster.

56. Rogers, S., (2009). “How to Crowdsource MPs' Expenses." The Guardian. [accessed 10th January 2015] Available from: http://www.theguardian.com/news/datablog/2009/jun/18/mpsexpenses-houseofcommons

57. Røpke, I., Christensen, T.H., \& Jensen, J.O. (2010). “Information and Communication Technologies: A New Round of Household Electrification." Energy Policy 38(4), p. 1764-1773.

58. Run That Town (2015). Available at: http://runthattown.abs.gov.au/. [Accessed 25 February 2015]

59. Salen, K. \& Zimmerman, E. (2003). Rules of Play: Game Design Fundamentals. Cambridge, Massachusetts: MIT Press. 
60. Santovec, M. L. (2011). Women, Socialization and Video Games. Women in Higher Education, 20(11), 8-9.

61. Sheppard, D. C. (2011). "Social Solutions for Climate Change Mitigation and Adaptation: Cross Cultural Lessons from Denmark to the Intersect." The Stanford Journal of Science, Technology \& Society, 4(1), p. 67-91.

62. Sicart, M., (2011). "Against Procedurality." Game Studies [Online] 11(3) [accessed 15th January 2015]. Available from: http://gamestudies.org/1103/articles/sicart_ap.

63. Simmhan, Y., Zhou, Q., \& Prasanna, V. (2011). “Semantic Information Integration for Smart Grid Applications." In Kim, J. \& Lee, M. (Eds.) Green IT: Technologies and Applications. London: Springer.

64. Spent (2011). Available at http:// playspent.org/ . [Accessed 18 March 2016]

65. Squire, K. "Video Games in Education." International Journal of Intelligent Games \& Simulation 2.1 (2003): 49-62.

66. Srivastava, L., \& Vakali, A. (2012). “Towards a Narrative-Aware Design Framework for Smart Urban Environments Urban Mobility: State of the Art and Gap Analysis," p. 166-177.

67. Stackelberg, P. Von, \& Jones, R. E. (2014). “Tales of Our Tomorrows: Transmedia Storytelling and Communicating About the Future." Journal of Futures Studies, 18(3), p. 57-76.

68. Stephenson, J., Barton, B., Carrington, G., Gnoth, D., Lawson, R., \& Thorsnes, P. (2010). “Energy Cultures: A Framework for Understanding Energy Behaviours.” Energy Policy, 38(10), p. 6120-6129.

69. Strengers, Y. (2011). “Designing Eco-feedback Systems for Everyday Life.” In Proceedings of the Annual Conference on Human Factors in Computing Systems. Vancouver, CA: Association for Computing Machinery.

70. Tsoukalas, L. H., \& Gao, R. (2008). “From Smart Grids to an Energy Internet: Assumptions, Architectures and Requirements." IEEE Deregulation, Restruction and Power Technologies 3, p. 94-98.

71. Vasconcelos, E., Lucena, C., Melo, G., Irving, M., Briot, J.-P., Sebba, V., \& Sordoni, A. (2009). “A Serious Game for Exploring and Training in Participatory Management of National Parks for Biodiversity Conservation: Design and Experience." Rio de Janeiro, BR: 2009 VIII Brazilian Symposium on Games and Digital Entertainment, p. 93-100.

72. Vervoort, J.M., Kok, K., van Lammeren, R., \& Veldkamp, T. (2010). “Stepping into Futures: Exploring the Potential of Interactive Media for Participatory Scenarios on Social-ecological Systems." Futures 42(6), p. 604-616.

73. Walker, G., Cass, N., Burningham, K., \& Barnett, J. (2010). “Renewable Energy and Sociotechnical Change: Imagined Subjectivities of 'the Public' and their Implications." 
74. Wark, M., (1994). Virtual Geography: Living with Global Media Events. Indianapolis, IN: Indiana University Press.

75. Weber, R. (2010). Internet of Things. Zürich, Berlin: Springer.

76. World Without Oil [website]. San Jose, CA: Corporation for Public Broadcasting, 2007. http:// worthwithoutoil.org [accessed 25 March 2015].

77. Wright, R., (2001). Nonzero: History, Evolution \& Human Cooperation: The Logic of Human Destiny (2nd ed) London: Abacus.

78. Wüstenhagen, R., Wolsink, M., \& Bürer, M. J. (2007). “Social Acceptance of Renewable Energy Innovation: An Introduction to the Concept." Energy Policy 35(5), p. 2683-2691.

79. Zyda, M. (2005). “From Visual Simulation to Virtual Reality to Games." Computer, 38(9), p. 2532.

\section{Ludography}

1. Australian Bureau of Statistics (2013). Run This Town [Game].

2. Brøderbund Maxis (1989). SimCity PC [Game].

3. Channel 4 (2014). Reverse the Odds iOS [Game].

4. Electronic Arts Maxis (2000). The Sims PC [Game].

5. Eklund, K., and Writerguy (2007). World Without Oil [Game].

6. Formula D Interactive. Eskom Energy Planner (2013) PC [Game].

7. InterFuel, LLC. (2006). Darfur is Dying [Web].

8. McKinney, (2011) Spent [Web]

9. Pande V., and Pande Laboratory (2000). Folding@home [Game].

10. Pollotta, T. (2010). Collapsus [Web/film].

11. Red Redemption, Ltd. (2011). Fate of the World: Tipping Point PC [Game].

12. Supercell (2012) Clash of Clans [iOS]

13. Zynga, (2009). Farmville [Facebook]

14. Zynga, (2009) Mafia Wars [Web]

\footnotetext{
${ }^{1}$ Research undertaken at Stanford shows a quantifiable 2\% drop in household energy use when consumers played The Energy Game (2015). See B. Reeves, Cummings, J. J., Scarborough, J. K., \& Yeykelis, L. (2015),

"Increasing Energy Efficiency With Entertainment Media An Experimental and Field Test of the Influence of a Social Game on Performance of Energy Behaviors" in Environment and Behavior, 47(1), p. 102-115.

2 Cass \& Walker (2009) note that environmental decisions based purely on rational, technical, "objective" and scientific assessments have been called into question and may not be generally accepted. Socially-situated
} 
values and beliefs are now widely understood to be centrally, even primarily important in determining outcomes of processes of decision-making (see also Haggett, 2009 and Walker et al., 2010).

${ }^{3}$ Multiplayer games, social games in which community is an integral part of game play, have interfaces that largely serve as a conduit for coordinated social processes. These games have become increasingly popular since the 1990s, with at least one major sustainability-themed multiplayer game in World Without Oil (2007). Broadly, social game play was named as one of the key growth areas in games in the 2014 Entertainment Software Association report, with $47 \%$ of those surveyed reporting that they engage in social games, an increase of 55\% over the previous year (ESA, 2014). Organisations aiming to encourage engagement with innovative ways of encouraging transitional energy behaviours are shown to increase impact substantially by targeting early adopters of innovations (Rogers, 2010). Early market adopters in this case may make up a substantial proportion of the population, as the potential market for "green" products and services is growing rapidly, as is the culture of participation in games and gaming (Prothero et al., 2010)

4 This evokes a cybernetic view of humanness. See B. Keogh (2014), "Cybernetic Memory and the Construction of the Posthuman Self in Videogame Play" in D.M. Weiss, Propen, A., \& C.E. Reid (Eds.) Design, Mediation, and the Posthuman (Lanham, Maryland, USA: Lexington Books, 2014), p. 233-248.

5 See section 5 for a discussion of serious games.

6 Tipping Point was designed to reflect an accurate model of climate change and the effects of policy and intervention over ecological disaster, created by Oxford University professor Myles Allen. Its design is in keeping with Mary Flanagan's description of the game structure in Critical Play (2013) as a "framework that designers can use to model the complexity of the problems that face the world and make them easier ... to comprehend," and to allow space to step outside of the game to think critically about these problems (2009, p. 249).

${ }^{7}$ For Frasca, the distinction between narrative and simulation is distinct and important; "in temporal terms, narrative is about what already happened while simulation is about what could happen." Frasca also highlights that the importance of simulations is not in their representation of conveying of a set of values, but in a player's exploration of "the mechanics of a dynamic system" (2004, p. 86).

8 Sarah Atkins has argued that repositioning or displacing a protagonist's point of view, creates new modes of audience engagement (2014, p. 159). Atkins proposes the establishment of a new methodology which she terms "displaced fiction" in which audiences experience shifts in time and identity in order to approach ethical and social issues from radically new perspectives (p. 165). In this view, new forms of narrative merge with cinematic and interactive to create experiences of complex topics, increasing deep understanding of given social issues and scenarios.

9 Folding@Home was designed by at Stanford University and uses inactive computer memory to run a programme that simulates protein-folding exercises on user devices, reporting progress back to users at intervals, and producing practically useful data for research in diseases like cancer and Alzheimer's disease. For more information and updates, see https:// folding.stanford.edu/. Investigate Your MP's Expenses, devised and promoted by The Guardian newspaper, provided open access to over 700,000 public expense documents and asked the public to work collaboratively to investigate and interrogate public archives, resulting in increased public awareness of expenditure of members of the UK House of Commons as well as identification of a number of very questionable expenditures. For more information and updates, see http://www.theguardian.com/news/datablog/2009/sep/18/mps-expenses-westminster-data-house-ofcommons.

10 Darfur is Dying was developed at the University of Southern California, and launched in partnership with the Reebok Human Rights Foundation and the International Crisis Group. Its in-game goal is for players to keep refugee camps healthy and functioning while protecting them from militia attacks. It also provides plenty of social context and opportunities for players to learn more about genocide in Darfur, as well as opportunities to contribute to efforts to assist in the crisis. For more information, see

http://www.gamesforchange.org/play/darfur-is-dying/

11 Nest was developed by former Apple engineers at Nest Labs in Palo Alto, California. For more information on Nest, visit https://nest.com/.

12 This supports suggestions by researchers that electricity delivery networks are likely to increasingly require intelligent systems interaction from users to achieve optimum efficiency and robustness (Nakarado, 1996).

13 See for example Francis da Costa, Rethinking the Internet of Things: A Scalable Approach to Connecting Everything (New York: Apress Publishing, 2013); Rolf H. Weber and Romana Weber, Internet of Things (New York: Springer, 2010). 